\title{
The weeping vocalization of the screaming hairy armadillo (Chaetophractus vellerosus), a distress call
}

\author{
Juan P. Amaya, ${ }^{*}$ Emmanuel Zufiaurre, Juan I. Areta, and Agustín M. Abba \\ Centro Regional de Investigaciones Científicas y Transferencia Tecnológica de La Rioja (CRILAR-CONICET), 5301 Anillaco, La \\ Rioja, Argentina (JPA) \\ IBICOPA-DACEFYN (Departamento académico de Ciencias Exactas Físicas y Naturales) UNLaR 5300 (JPA) \\ CONICET-Universidad de Buenos Aires. Instituto de Ecología, Genética y Evolución de Buenos Aires (IEGEBA), Grupo de \\ Estudios sobre Biodiversidad en Agroecosistemas (GEBA), C1428EHA Ciudad Autonoma de Buenos Aires, Argentina (EZ) \\ Universidad de Buenos Aires, Facultad de Ciencias Exactas y Naturales, Departamento de Biodiversidad y Biología \\ Experimental, C1428EHA Ciudad Autónoma Buenos Aires, Argentina (EZ) \\ Instituto de Bio y Geociencias del Noroeste Argentino (IBIGEO-CONICET), Rosario de Lerma, A4405 Salta, Argentina (JIA) \\ Centro de Estudios Parasitológicos y de Vectores (CEPAVE), Facultad de Ciencias Naturales y Museo (UNLP), CONICET, La \\ Plata, B1902CHX Buenos Aires, Argentina (AMA)
}

*Correspondent: juanentuculandia@gmail.com

\begin{abstract}
Distress calls are signals given by individuals experiencing physical stress such as handling by a predator. These calls have been recorded in numerous phylogenetically distant vertebrate species, and share certain acoustic features, such as high amplitude, broadband, and rich harmonic structure. Screaming hairy armadillos (Chaetophractus vellerosus) sometimes give a high-amplitude weeping call when captured by predators or disturbed by humans. We provide an acoustic characterization of this call using recordings of hand-held wild individuals, and test whether it constitutes a distress signal. The weeping call was a harsh, loud, broadband, long sound, composed of five note types: crying, inhaled, inhaled sobbing, exhaled sobbing, and grunt notes. Crying notes were the most common, distinctive, and loudest sounds. The proportion of armadillos that called when disturbed was between nearly five to seven times higher than when treated with care. Likewise, 223 hunters reported armadillos consistently weeping when trapped by dogs, and no weeping was heard in natural undisturbed conditions. Our data support a distress signal role for the weeping call.
\end{abstract}

Las vocalizaciones de pánico son señales producidas por individuos cuando se encuentran en contextos de estrés físico, como ser capturados por un depredador. Estas vocalizaciones se han registrado en numerosas, y filogenéticamente distantes, especies de vertebrados, y las mismas comparten varias características acústicas, como alta amplitud, banda ancha y una rica estructura armónica. Los piches llorones (Chaetophractus vellerosus) son armadillos que a menudo emiten una fuerte vocalización llorosa cuando son capturados por depredadores o perturbados por humanos. En este trabajo caracterizamos acústicamente esta vocalización llorosa a partir de grabaciones realizadas en individuos libres que fueron capturados momentáneamente, y evaluamos si corresponde a una vocalización de pánico. La vocalización llorosa fue de larga duración y estuvo compuesta por sonidos ásperos, fuertes y de banda ancha. La misma no presentó dimorfismo sexual y se identificaron cinco tipos de notas: lloradas, inhaladas, sollozas inhaladas, sollozas exhaladas y graznidos. Las notas lloradas fueron los sonidos predominantes, distintivos y de mayor amplitud de la vocalización. La proporción de piches llorones que vocalizaron cuando fueron capturados y perturbados fue entre cinco y siete veces mayor que cuando fueron manipulados con cuidado. Del mismo modo, 223 cazadores informaron que los piches llorones comúnmente emiten vocalizaciones llorosas cuando estos son capturados por perros, y esta vocalización no fue producida por individuos que se encontraban libres en condiciones naturales inalteradas. Nuestros datos respaldan designar a la vocalización llorosa como una vocalización de pánico.

Key words: $\quad$ acoustic structure, distress signals, predator defense, Xenarthra

Distress calls are signals given by individuals experiencing physical stress such as when captured or handled by a predator, and are thought to have an antipredatory function (Riessen and Sprules 1990; Manteuffel et al. 2004; Caro 2005). These calls

(C) 2019 American Society of Mammalogists, www.mammalogy.org 
have been recorded in numerous phylogenetically distant vertebrate species, including frogs (Hödl and Gollman 1986), lizards (Labra et al. 2013), birds (Venuto et al. 2001), and mammals (Klump and Shalter 1984; August and Anderson 1987). Among these groups, distress calls are broadly convergent and share many general acoustic features, such as high amplitude, wide frequency range (i.e., broadband), and rich harmonic structure with sound energy distribution over a wide range of frequencies, and often exhibit nonlinear phenomena (Møller and Nielsen 2010; Bradbury and Vehrencamp 2011). Distress calls typically have a broad audience, because their function is hypothesized to trigger intra- or interspecific behavioral responses resulting in a defense against predators. The importance of a straightforward message capable of reaching a broad audience has been inferred to be the main cause of the acoustic similarities of these calls among different taxa (Morton 1977; Aubin 1989; Ehret 2006). For instance, prey may vocalize to scare away the predator, to elicit help from conspecifics, or to draw attention from other predators that might attack the initial predator giving the prey an opportunity to escape (Conover 1994; Godfray 1995; Griffin 2008).

Screaming hairy armadillos (Chaetophractus vellerosus) are solitary and generally silent, but often give a highamplitude weeping call when captured by predators (Abba et al. 2011). This weeping is so conspicuous that the species is known by the local Spanish name of "piche llorón" (i.e., "weeping armadillo"). Despite a wealth of data on its ecology and behavior (Greegor 1985; Abba et al. 2012), the weeping call has never been described in detail and its context and frequency of emission remain poorly understood. This call is apparently given only in distressful situations, and only $5.8 \%$ of 240 screaming hairy armadillos handled with care gave the weeping call (Abba et al. 2011). However, it has been suggested that the proportion of weeping individuals would increase when captured by carnivores or other natural predators (Abba et al. 2011).

Here, we hypothesize that the weeping call of the screaming hairy armadillo is a distress call. Since distress calls are aimed at a wide audience including conspecifics and heterospecifics, they may be less likely to exhibit sexual dimorphism than signals employed in inter-sexual communication (Dabbs and Mallinger 1999; Vignal and Kelley 2007). Thus, we predict that if weeping calls of the screaming hairy armadillo are distress calls, they should: 1) be characterized by broadband, high-amplitude, and rich harmonic structure; 2) lack sexual dimorphism; 3) be given by a higher proportion of individuals when the level of threat increases (e.g., when purposely disturbed than when being handled with care); and 4) be given in situations of extreme danger (e.g., when trapped by a predator), and not routinely during normal daily activities.

In this study, we provide a detailed description and acoustic characterization of the weeping call of the screaming hairy armadillo from recordings of eight hand-held wild individuals, and evaluate whether this call can be considered a distress call by testing the four predictions described above.

\section{Materials ANd Methods}

Recording of calls.-Field studies were conducted at the

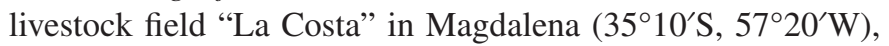
Buenos Aires, Argentina. We captured 28 individuals (15 males and 13 females) of screaming hairy armadillo by hand during sampling sessions between June and August 2017. Eight individuals called after disturbing them with our hands in an attempt to elicit calls (see "Context of emission" below; Supplementary Data SD1). When a caller individual was captured, it was recorded until the animal stopped weeping, so we recognized a call as all notes produced by an individual in each recording session. When an individual stopped weeping, we held it in hand for an additional 2-3 min while we took body measurements and recorded weight. Recordings were made using a Zoom $\mathrm{H} 2 \mathrm{n}$ digital hand recorder system with built-in microphones (Zoom Corp., Tokyo, Japan; sample rate of $44.1 \mathrm{kHz}$ and 24-bit depth). The gain of the recorder was the same for all recordings. To ensure good-quality recordings, the recorder was held near the mouth of the vocalizing individual without interfering in its behavior. All procedures followed the guidelines of the American Society of Mammalogists for the use of wild mammals in research (Sikes et al. 2016).

Acoustic characterization.-We identified five note types in the weeping call of the screaming hairy armadillo: crying notes, inhaled notes, inhaled sobbing notes, exhaled sobbing notes, and grunt notes (Figs. 1 and 2). Crying, inhaled, and grunt notes could be clearly and unambiguously distinguished based on their spectrographic structure, but inhaled and exhaled sobbing notes could not. To distinguish the inhaled and exhaled sobbing notes which occurred alternately (see "Results"), we listened to the recordings at normal speed and at various low-speed playback rates that allowed us to recognize the sound of air entering (inhaled sobbing notes) and exiting (exhaled sobbing notes) the respiratory tract. This allowed us to correctly and unambiguously identify to note type $97.8 \%$ of 1,139 notes (see "Results" for more details).

We analyzed all unambiguously identified calls to quantify the number of each note type per call and to acoustically characterize them. Acoustic measurements were taken from up to 10 randomly chosen samples of each note type per individual (see Supplementary Data SD2 for acoustic definitions and sampling). All acoustic measurements (except fundamental frequency) were made with Raven Pro 1.4 (http:// www.birds.cornell.edu/raven) using the following spectrogram parameters: window-type: Hann; size: 1,024 samples (= $21.3 \mathrm{~ms}$ ); $3 \mathrm{~dB}$ filter and with: $67.4 \mathrm{~Hz}$; time grid overlap: $50 \%$; hop size: 512 samples (= $10.7 \mathrm{~ms}$ ); frequency grid-DFT size: 4,096 samples; grid spacing: $11.7 \mathrm{~Hz}$. Fundamental frequency of crying notes was analyzed in Praat (Boersma and Weenink 


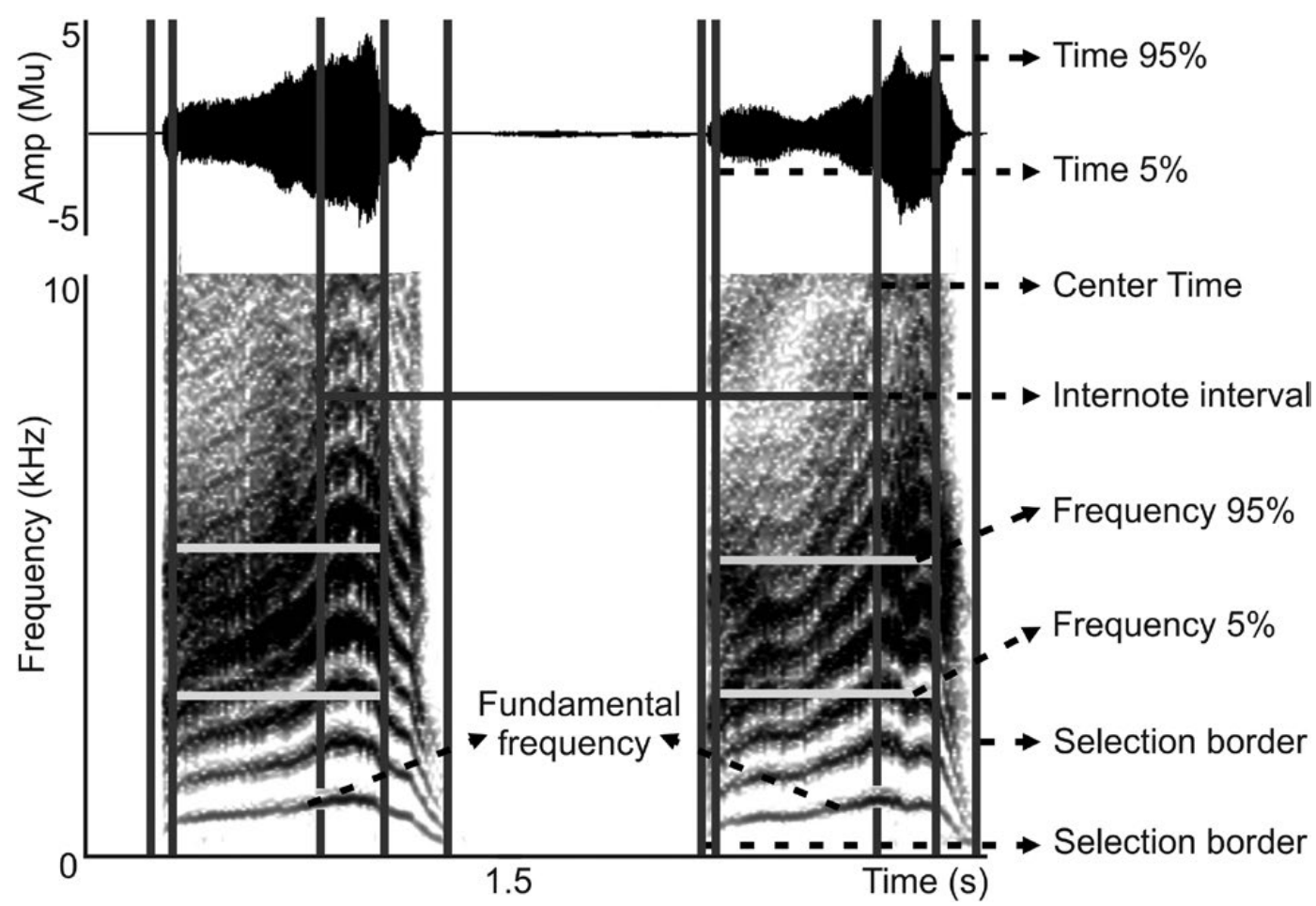

Fig. 1.-Delimitation of selection borders and variables used for the quantitative acoustic characterization of the note types of the weeping call of the screaming hairy armadillo (Chaetophractus vellerosus). Here, we show the selection borders and measurements in two successive crying notes.

2006) using the following spectrogram parameters: windowtype: Hann; window length $=0.02 \mathrm{~s}$; time steps $=1,000$; frequency steps $=250$; dynamic range $=50 \mathrm{~dB}$. All recordings were band-pass filtered between 0 and $200 \mathrm{~Hz}$ in Raven Pro 1.4 to eliminate sources of distortion in central-tendency acoustic measurements.

We delimited note types in Raven Pro 1.4 with selection borders spanning the total note duration in the time axis (selection borders were placed at points in which the waveform changed its general repetitive pattern and reached minimum energy values) and from 0 to $22.05 \mathrm{kHz}$ in the frequency axis (Fig. 1). Temporal measurements were taken in this original selection, while frequency measurements were taken within a new selection delimited by the duration $90 \%$ of the original selection. We measured two temporal variables: duration $90 \%$ (ms) and inter-note interval (ms); and four frequency measurements: average fundamental frequency (Hz; only in crying notes), peak frequency $(\mathrm{Hz})$, frequency $5 \%(\mathrm{~Hz})$, and frequency $95 \%$ (Hz; see Supplementary Data SD2 for definitions of acoustic parameters). Finally, we visually inspected spectrograms looking for nonlinear phenomena in all note types. Nonlinear phenomena result from the aperiodic vibrations of the vocal folds during the phonation process (Wilden et al. 1998). Examples of nonlinear phenomena are: deterministic chaos, characterized by a broadband spectrum with some remaining periodic energy, which appears as banding in the spectrogram; and subharmonics, identified by additional harmonic bands in the spectrum between the fundamental frequency and its related harmonics (Wilden et al. 1998; Fitch et al. 2002). To improve the level of visual detail, all spectrograms show energy contained between 0 to $10 \mathrm{kHz}$ because this frequency range included more than $95 \%$ of the energy of the notes (Fig. 1).

Since crying notes were identified as the most relevant sound (i.e., predominant and conspicuous) of the weeping call and were produced by all individuals, we aimed to provide a more precise description of this note type. Spectrograms suggested differences in the amount of disorder in the lower half and upper half of crying notes; we quantified these differences by measuring the average entropy $(\mathrm{u})$ in two selections: from $0 \mathrm{~Hz}$ to frequency $5 \%$ and a second one from frequency $5 \%$ to frequency $95 \%$. Despite the different amounts of energy within each selection, each spanned ca. $50 \%$ of the bandwidth: the first selection included the fundamental frequency and up to the third-fourth harmonic, while the second selection included from the third-fourth harmonic up to the sixth-seventh harmonic (Fig. 1). Additionally, we evaluated the presence of sexual dimorphism in crying notes (see "Statistical analyses").

Context of emission.-To test whether the weeping call occurs more often when an individual is disturbed than when being handled with care, we compared the proportion of individuals giving calls in the present paper against previous studies (Abba et al. 2011, 2017; AMA, pers. obs.). In the present paper, we purposely disturbed the armadillos (i.e., the captured individuals were gently shaken and rubbed with the fingers on their carapaces), while in Abba et al. (2011, 2017; AMA, pers. obs, ) armadillos were treated with great care to minimize stress (i.e., without sudden movements and carefully keeping nervous individuals in cloth bags). To show how often this call 


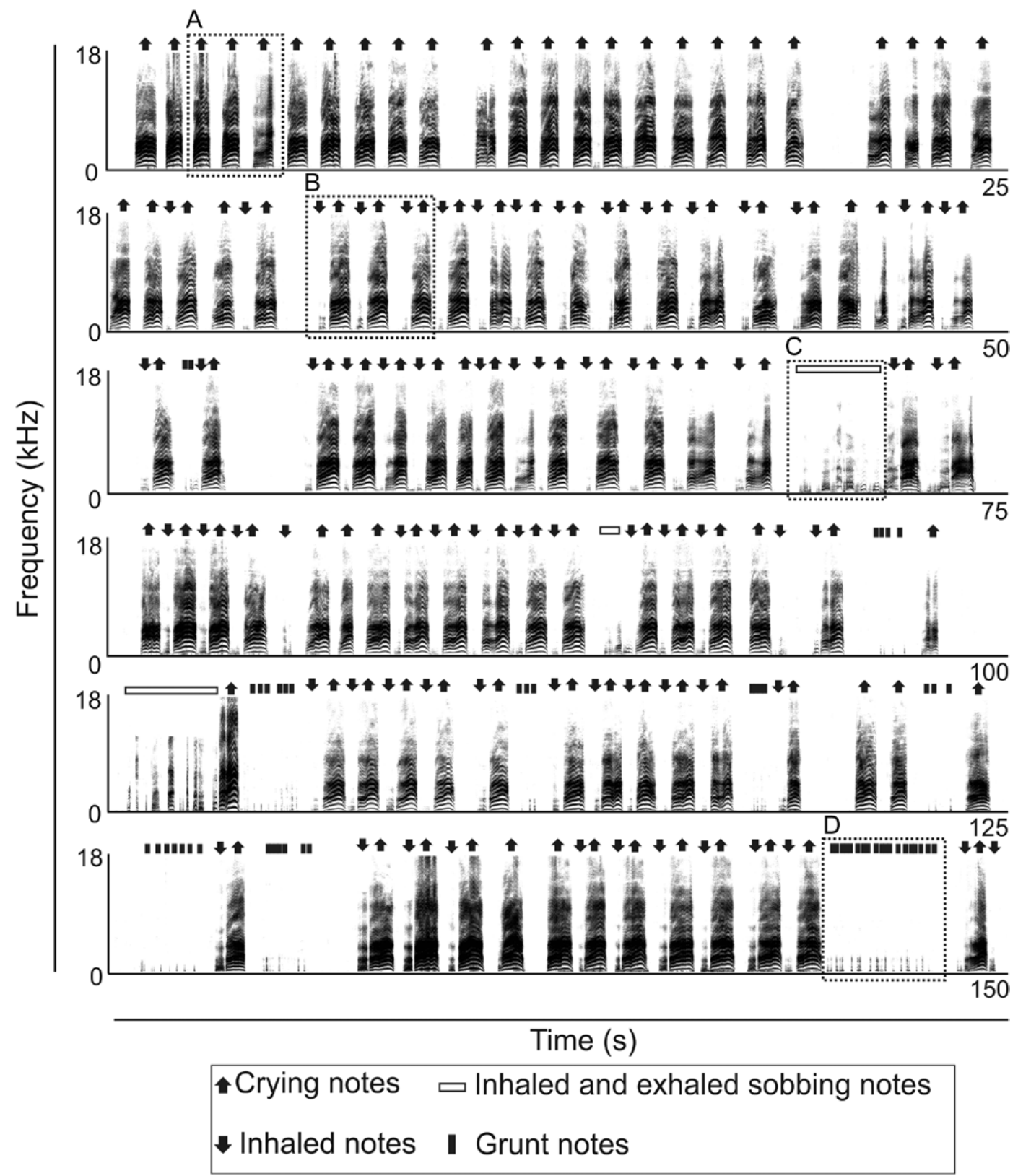

Fig. 2.- Spectrogram of one full recording of the weeping call of the screaming hairy armadillo (Chaetophractus vellerosus) showing the five note types and their temporal organization (i.e., syntax). A) Crying notes with silence interval between successive notes. B) Crying notes associated with inhaled notes. C) Sequence of exhaled and inhaled sobbing notes. D) Sequence of grunt notes. Insets show the segments of this call shown in more detail in Fig. 3.

occurs in normal daily activities without handling, we compare our data to the frequency of occurrence of the weeping call in other field studies, including 400 hours in 61 fieldwork days across 6 years (Abba et al. 2017) on the same area of this study, and $1,500 \mathrm{~h}$ in 220 fieldwork days at other localities (see Abba 2008; Abba et al. 2015a, 2015b). Finally, we provide the results of informal interviews with 223 local inhabitants who regularly hunted armadillos with dogs, carried out between 2005 and 2018 within the range of the screaming hairy armadillo (AMA, pers. obs.). The interviewees were considered qualified informants if they had lived in the area for at least 10 years, and if they could unambiguously recognize the species. These qualified informants described the times at which they heard the vocalization of the screaming hairy armadillo, and the characteristics and context of emission of the call.

Statistical analyses. - To characterize the note types in the weeping call of screaming hairy armadillos, we calculated the mean value of acoustic measurements of each note type per individual. We assessed sexual dimorphism in crying notes by comparing all the acoustic measurements between both sexes. Given the low number of individuals, we assessed sexual dimorphism in crying notes by visually comparing the values of the acoustic parameters. When means and SDs did not overlap, we considered the differences to be statistically significant. To 
identify syntactic patterns of the weeping vocalization, we calculated the probability of occurrence of a note type in relation to the preceding note type using a first-order Markov process (Grinstead and Snell 1997). We constructed a transition matrix showing the transition probabilities between the five note types (Supplementary Data SD4). Because each note type could be potentially succeeded by five note types, sequences of two notes were considered nonrandom when the probability of occurrence was greater than 0.2. Data are presented as mean $\pm S D$.

\section{RESULTS}

Acoustic characterization.-We recorded the weeping call of eight wild individuals of screaming hairy armadillo while being hand-held (four adult males, one subadult male, and three adult females). The weeping call consisted of five note types (Figs. 2 and 3). In total, we recorded 1,139 notes, $44.2 \%$ of which were crying notes emitted by all individuals ( $n=238$ from males, 257 from females), $20.2 \%$ were inhaled notes produced by all but one individual (subadult male) $(n=120$ from males, 106 from females), $15.8 \%$ were exhaled sobbing notes emitted by all individuals ( $n=109$ from males, 68 from females), $11.1 \%$ were inhaled sobbing notes emitted by all but two individuals (one female and one male) ( $n=78$ from males, 46 from females), and $8.2 \%$ were grunt notes produced by three individuals (one female and two males) ( $n=52$ from males, 40 from females). We could not confidently classify only $2.2 \%$ of the notes ( $n=14$ from males, 11 from females), but these were low-amplitude and short-duration sounds.

The five note types were repeated a variable number of times during each call, creating considerable variation in the general syntactic pattern of the vocalization (Fig. 2; Supplementary Data SD5). Nevertheless, we found reliable syntactic patterns between successive notes: inhaled notes were always emitted

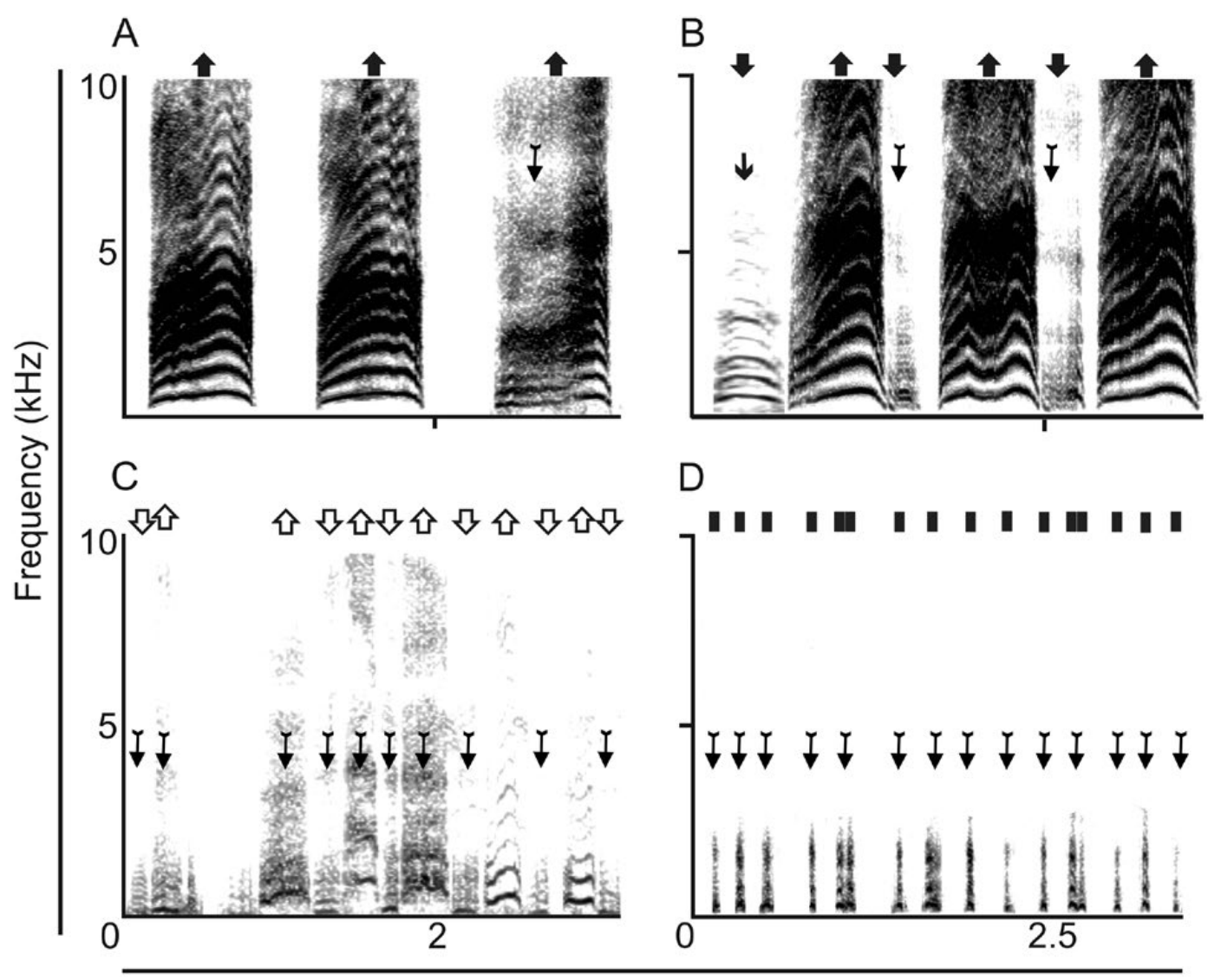

Time (s)

\begin{tabular}{|ll|}
\hline Crying notes & I Grunt notes \\
$\downarrow$ Inhaled notes & $\downarrow$ Note with deterministic chaos \\
$\nwarrow$ Inhaled sobbing notes & $\downarrow$ Note with subharmonics \\
仓 Exhaled sobbing notes & \\
\hline
\end{tabular}

Fig. 3. - Spectrograms showing structural details of notes of the weeping call of the screaming hairy armadillo (Chaetophractus vellerosus). A) Crying notes with silence interval between successive notes. B) Crying notes associated with inhaled notes. C) Sequence of exhaled and inhaled sobbing notes. D) Sequence of grunt notes. See Fig. 2 for the placement of these notes in a full call. 
just before a crying note, so the inter-note interval between two successive inhaled notes was always occupied by a crying note (Figs. 2 and 3; Supplementary Data SD4 and SD5); crying notes could either be separated by a silent inter-note interval or by an intervening inhaled note (Figs. 2 and 3; Supplementary Data SD4 and SD5); inhaled and exhaled sobbing notes occurred as a quick sequence of short inhaled and exhaled notes, so inhaled sobbing notes were always followed by exhaled sobbing notes and exhaled sobbing notes were frequently followed by inhaled sobbing notes (Figs. 2 and 3; Supplementary Data SD4 and SD5); finally, grunt notes were predominantly followed by grunt notes (Figs. 2 and 3; Supplementary Data SD4 and SD5).

Crying notes were exhaled sounds and constituted the most conspicuous and predominant sound in the calls. They were the longest note type of the call and were composed of multiple harmonic bands, with a low fundamental frequency, and with the peak frequency occurring either in the fourth or fifth harmonic (Figs. 2, 3, and 4A and B; Supplementary Data SD3). The average entropy was statistically different between two frequency selections in the crying notes, both in males $(n=5)$ and females $(n=3)$; average entropy between $0 \mathrm{~Hz}$ and frequency $5 \%$ was lower than between frequency 5\%-frequency $95 \%$ (Fig. 4C). This means that the lowest portion of the frequency spectrum of the sound was more ordered than the comparatively more disordered higher-frequency segment of the notes. Nonlinear phenomena were uncommon with deterministic chaos present in only $3.1 \%$ of the crying notes (Fig. $3 \mathrm{~A}$ ). We were unable to compare the acoustic features of crying notes between sexes statistically. However, visual inspection of average acoustic values shows that crying notes are indistinguishable between females and males (Fig. 4; Supplementary Data SD3).

Inhaled notes had a variable spectral composition with ubiquitous occurrence of nonlinear phenomena; $81.8 \%$ of inhaled notes possessed deterministic chaos but only $4.1 \%$ had subharmonics (Fig. 2B).

Inhaled and exhaled sobbing notes were produced at the beginning of a call or after a long sequence of crying and inhaled notes (Supplementary Data SD5). The production of inhaled and exhaled sobbing notes ends with the emission of a sequence of crying notes (Fig. 2 and Supplementary Data SD5). Both sobbing notes had a variable spectral structure with a notable occurrence of deterministic chaos, which was present in $84.3 \%$ of inhaled sobbing and in $84.8 \%$ of exhaled sobbing notes (Fig. 3C).

Grunt notes were exhaled sounds and were the shortest sounds, and also had short inter-note intervals (Figs. 2-4; Supplementary Data SD3). Grunt notes were the lowestpitched sounds with a less-variable spectral structure, without subharmonics but always with deterministic chaos (Figs. 2 and 3D).

Context of emission. - The proportion of hand-held armadillos that called when disturbed ( $28.5 \%$ of 28 individuals) was between nearly five to over seven times higher than the proportion of those that called when treated with care (5.8\% of 237 captures in Abba et al. [2011] and 4\% of 566 captures in Abba et al. [2017]; AMA, pers. obs.). Thus, the emission of the weeping call was clearly related to higher distress levels in the armadillos. Moreover, AMA never heard a weeping call coming from free-living individuals


\section{Note type}

Fig. 4.-Acoustic features of the five note types of the weeping call of the screaming hairy armadillo (Chaetophractus vellerosus). A) Temporal measurements of note types from all individuals. B) Frequency measurements of note types from all individuals. C) Average entropy of crying notes in two selections each encompassing ca. 50\% of the band width ( $0 \mathrm{~Hz}$ to frequency $5 \%$ and frequency $5 \%$ to frequency $95 \%$ ). Acoustic features of crying notes in adult males and females are indicated separately. Data from all individuals in Supplementary Data SD1. 
during 61 days of previous fieldwork at our study site (Abba et al. 2017), or during 220 fieldwork days at other localities within the range of the screaming hairy armadillo (see Abba 2008; Abba et al. 2015a, 2015b). This absence of weeping calls shows that it is not used regularly during daily activities. The responses of 223 local hunters reported that armadillos consistently called when trapped by their dogs; this involved an unknown but large number captures (likely over 1,000 individuals).

\section{Discussion}

In this paper, we acoustically characterize the weeping call of the screaming hairy armadillo, and explore its functional significance. The weeping call is a harsh, loud, broadband, and long sound composed of five note types: crying notes, inhaled notes, inhaled sobbing notes, exhaled sobbing notes, and grunt notes. The general arrangement and number of the note types were highly variable between individuals of both sexes; however, some predictable syntactic patterns between successive note types were evident. Crying notes were the most common, distinctive, and loudest sounds in the call, and there were no differences in acoustic parameters among sexes. The acoustic structure, probable lack of sexual dimorphism, and the behavioral contexts in which individuals of the screaming hairy armadillo produced the weeping call (hand-held disturbance and dog trapping) indicate that this is a distress call.

The structure of sounds often provides clues to their function (August and Anderson 1987). According to the Motivation Structural Rules, a sound with frequency modulation and wide frequency bandwidth corresponds to an emission where fear and aggression are interacting (Morton 1977). The acoustic features of the weeping call, but especially of the crying notes, are those expected for vocalizations motivated by fear or aggression (see Aubin and Brémond 1992; Jurisevic and Sanderson 1994). Moreover, distress calls frequently exhibit nonlinear phenomena such as deterministic chaos and subharmonics (Lingle et al. 2012; Labra et al. 2013). Nonlinear phenomena are thought to result from "over-blowing" the sound production system (Fitch et al. 2002) and may signal a higher level of distress, leading to heightened responses by receivers (Riede et al. 2007). The presence of nonlinear phenomena further supports fear as a possible motivation of the weeping vocalization.

The weeping call is complex and highly variable in syntax. It is composed of several components that vary greatly in length and intensity and which possess highly contrasting structural features. The weeping call includes some notes produced by the exhalation and others by the inhalation of air. This raises the question as to which of the notes in the weeping call have a communicative function and which ones result incidentally from the process of producing the communicative notes themselves. In this framework, we suggest that the loud exhaled crying notes are the main carriers of the distress signal while the inhaled notes are incidental byproducts created by the intrinsic bio-mechanical properties of the vocal apparatus stimulated by the sustained and intense physical activities required to produce the crying notes. Even if the main communicative function is concentrated in the crying notes, the incidentally produced inhaled notes can also provide information about the status of the caller. For example, an individual weeping with crying notes separated by silences may be less distressed than an individual weeping with inhaled notes in between the crying notes, much as happens with the cries of human infants (Grau et al. 1995). Hence, those notes incidentally produced during inhalation would still possess a communicative value. The communicative function of three relatively common note types (inhaled sobbing notes, exhaled sobbing notes, and grunt notes) is unknown. For example, exhaled sobbing and grunt notes are relatively soft and may be used in communication at close range, while inhaled sobbing notes may be incidental byproducts of the production of the higher-amplitude sounds. Future studies on the anatomical features of the vocal chords and tract of $C$. vellerosus are necessary to understand the relationship between the components of the call and the kinematics behind their emission. Likewise, discriminating the communicative role (if any) of the different notes in the weeping call of $C$. vellerosus is a promising research avenue to understand distress calls.

Solitary species are less inclined to give distress calls than flocking or gregarious species (Greig-Smith 1982; Inglis et al. 1982 ), and this is in agreement with the relatively low proportion of armadillos that called in our study. However, individuals were at least five times more likely to vocalize when disturbed in the hand than when being treated with care. This marked difference in the production of the weeping call suggests that greater stress increases the chances of producing this call. Likewise, the reports of over a thousand armadillos weeping when in the mouth of dogs used for hunting them, indicate that this is a distress call and not merely a sound given when simply disturbed.

Who is the target audience and what is the function of the weeping call? The screaming hairy armadillo is a solitary species, thus it seems unlikely that the weeping calls are directed mostly at conspecifics. Playback experiments should provide rewarding answers on the audience and behaviors triggered by the weeping call. These experiments should focus on testing its proximate role, such as whether this vocalization is used to startle predators (Perrone 1980; Conover 1994; Neudorf and Sealy 2002), to seek assistance from conspecifics (Rohwer et al. 1976), or to attract a second predator that may attack the first one and thereby allow the caller to escape (Högstedt 1983; Schuett and Gillingham 1990; Koenig et al. 1991). Additionally, ultimate explanations can also be tested by evaluating whether the benefits to the caller are not direct but rather indirect, by for example increasing the probability of its kin avoiding a similar fate (Hill 1986). Although the specific mechanisms through which the weeping call operates remain unknown, we have provided critical evidence based on its acoustic structure and behavioral context that support it constituting a distress call. 


\section{ACKNOWLEDGMENTS}

We are grateful to three anonymous reviewers and to R. Ojeda for providing critical reviews and numerous suggestions that improved previous drafts of the manuscript. We thank E. Person for English revision. We thank the local inhabitants that regularly hunt armadillos for providing key information on the weeping calls. The Ministerio de Asuntos Agrarios granted working permits. Support was provided by a CONICET postdoctoral fellowship to J. Amaya.

\section{SupPlementary Data}

Supplementary data are available at Journal of Mammalogy online.

Supplementary Data SD1.-Video recording of an individual screaming hairy armadillo (Chaetophractus vellerosus) producing the weeping calls while hand-held.

Supplementary Data SD2.-Acoustic parameters used to quantify the weeping call of the screaming hairy armadillo (Chaetophractus vellerosus).

Supplementary Data SD3.-Acoustic measurements of the five note types (crying, inhaled, exhaled sobbing, inhaled sobbing, or grunt notes) of the weeping call in eight individuals (four adult males, one subadult male and three adult females) of the screaming hairy armadillo (Chaetophractus vellerosus). For each individual, we provide their weight in parentheses. Data are presented as mean $\pm S D$ [range].

Supplementary Data SD4.-Transition matrix indicating reliable syntactic patterns between successive notes types of the weeping vocalization of the screaming hairy armadillo (Chaetophractus vellerosus). Bold numbers are nonrandom significant transitions, normal numbers are not nonrandom significant transitions.

Supplementary Data SD5.-Schematic representation of the syntax (number and order of note types) in the weeping calls of all individuals of the screaming hairy armadillo (Chaetophractus vellerosus) recorded in this study. Each scheme is preceded by the individual's identity. Each box represents X number of notes of each of the recognized note types (crying, inhaled, exhaled sobbing, inhaled sobbing, or grunt notes).

\section{Literature Cited}

AвBA, A. M. 2008. Ecología y conservación de los armadillos (Mammalia, Dasypodidae) en el noreste de la provincia de Buenos Aires, Argentina. Doctoral thesis, Facultad de Ciencias Naturales y Museo, UNLP, La Plata, Buenos Aires, Argentina.

Abba, A. M., V. V. Benitez, and S. R. Doyle. 2017. Population ecology of Chaetophractus vellerosus: the first report for an armadillo in South America. Zoologia (Curitiba) 34:e20785.

Aвba, A. M., G. H. Cassini, M. H. Cassini, and S. F. Vizcaino. 2011. Natural history of the screaming hairy armadillo Chaetophractus vellerosus (Mammalia: Xenarthra: Dasypodidae). Revista Chilena de Historia Natural 84:51-64.

Abba, A. M., G. H. Cassini, G. Valverde, M. Tilak, S. F. Vizcaíno, M. Superina, And F. Delsuc. 2015a. Morphological and molecular systematics of hairy armadillos (Xenarthra; Dasypodidae;
Euphractinae) and the taxonomic status of the Andean hairy armadillo (Chaetophractus nationi). Journal of Mammalogy 96:673-689.

Abba, A. M., M. F. Tognelli, V. P. Seitz, J. B. Bender, And S. F. Vizcaíno. 2012. Distribution of extant xenarthrans (Mammalia: Xenarthra) in Argentina using species distribution models. Mammalia 76:123-136.

Abba, A. M., E. Zufiaurre, M. Codesido, P. A. Gado, and D. BiLENCA. 2015b. Distribución de tres especies de armadillos en la región pampeana comprendida en la provincia de Buenos Aires, Argentina. Mastozoología Neotropical 22:359-365.

Aubin, T. 1989. The role of frequency modulation in the process of distress calls recognition by the starling (Sturnus vulgaris). Behaviour 108:57-72.

Aubin, T., AND J. C. BRÉMOND. 1992. Perception of distress call harmonic structure by the starling (Sturnus vulgaris). Behaviour 120:151-163.

August, P. V., And J. G. T. Anderson. 1987. Mammal sounds and motivation-structural rules: a test of the hypothesis. Journal of Mammalogy 68:1-9.

Boersma, P., And D. Weenink. 2006. Praat (version 4.5) [Computer software]. Institute of Phonetic Sciences, Amsterdam, the Netherlands.

Bradbury, J. W., and S. L. Vehrencamp. 2011. Environmental Signals. Pp. 561-610 in Principles of animal communication (J. W. Bradbury and S. L. Vehrencamp, eds). Sinauer Associates, Sunderland, Massachusetts.

CARo, T. 2005. Antipredator defenses in birds and mammals. University of Chicago Press, Chicago, Illinois.

Conover, M. R. 1994. Stimuli eliciting distress calls in adult passerines and response of predators and birds to their broadcast. Behaviour 131:19-37.

DabBS, J. M., JR., AND A. Mallinger. 1999. High testosterone levels predict low voice pitch among men. Personality and Individual Differences 27:801-804.

Ehret, G. 2006. Common rules of communication sound perception. Pp. 85-114 in Behavior and neurodynamics for auditory communication (J. S. Kanwal and G. Ehret, eds). Cambridge University Press, Cambridge, United Kingdom.

Fitch, W. T., J. Neubauer, and H. Herzel. 2002. Calls out of chaos: the adaptive significance of nonlinear phenomena in mammalian vocal production. Animal Behaviour 63:407-418.

Godfray, H. C. J. 1995. Communication between the first and third trophic levels: an analysis using biological signalling theory. Oikos 72:367-374.

Grau, S. M., M. P. Robb, and A. T. Cacace. 1995. Acoustic correlates of inspiratory phonation during infant cry. Journal of Speech and Hearing Research 38:373-381.

GREEGOR, D. H. 1985. Ecology of the little hairy armadillo Chaetophractus vellerosus. Pp. 397-405 in The evolution and ecology of armadillos, sloths and vermilinguas (G. G. Montgomery, ed.). Smithsonian Institution Press, Washington, D.C. and London, United Kingdom.

Greig-Smith, P. W. 1982. Distress call in woodland birds. Animal Behaviour 30:299-301.

GRIFFIN, A. S. 2008. Social learning in Indian mynahs, Acridotheres tristis: the role of distress calls. Animal Behaviour 75:79-89.

Grinstead, C. M., and J. L. Snell. 1997. Markov chains. Pp. 405470 in Introduction to probability (C. M. Grinstead and J. L. Snell, eds.). American Mathematical Society, Pacific Grove, California.

HILl, G. E. 1986. The function of distress calls given by tufted titmice (Parus bicolor): an experimental approach. Animal Behaviour 34:590-598. 
HöDl, W., And G. Gollman. 1986. Distress calls in Neotropical frogs. Amphibia-Reptilia 7:11-21.

HöGSTEDT, G. 1983. Adaptation unto death: function of fear screams. The American Naturalist 121:562-570.

Inglis, I. R., M. R. Fletcher, C. J. Feare, P. W. Greig-Smith, and S. LAND. 1982. The incidence of distress calling among British birds. Ibis 124:351-355.

Jurisevic, M. A., AND K. J. SANDERSON. 1994. Alarm vocalizations in Australian birds: convergent characteristics and phylogenetic differences. Emu-Austral Ornithology 94:69-77.

Klump, G. M., AND M. D. Shalter. 1984. Acoustic behaviour of birds and mammals in the predator context; I. Factors affecting the structure of alarm signals. II. The functional significance and evolution of alarm signals. Zeitschrift für Tierpsychologie 66:189-226.

Koenig, W. D., M. T. Stanback, P. N. Hooge, and R. L. Mumme. 1991. Distress call in the acorn woodpecker. Condor 93:637-643.

Labra, A., G. Silva, F. Norambuena, N. Velásquez, and M. Penna. 2013. Acoustic features of the weeping lizard's distress call. Copeia 2013:206-212.

Lingle, S., M. T. Wyman, R. Kotrba, L. J. Teichroeb, and C. A. Romanow. 2012. What makes a cry a cry? A review of infant distress vocalizations. Current Zoology 58:698-726.

Manteuffel, G., B. PupPe, AND P. C. SchÖN. 2004. Vocalization of farm animals as a measure of welfare. Applied Animal Behaviour Science 88:163-182.

Møller, A. P., AND J. T. Nielsen. 2010. Fear screams and adaptation to avoid imminent death: effects of genetic variation and predation. Ethology Ecology \& Evolution 22:183-202.

Morton, E. S. 1977. On the occurrence and significance of motivation-structural rules in some bird and mammal sounds. The American Naturalist 111:855-869.

Neudorf, D. L., ANd S. G. Sealy. 2002. Distress calls of birds in a Neotropical cloud forest. Biotropica 34:118-126.
Perrone M., JR. 1980. Factors affecting the incidence of distress calls in passerines. The Wilson Bulletin 92:404-408.

Riede, T., A. C. ArCadi, ANd M. J. OWren. 2007. Nonlinear acoustics in the pant hoots of common chimpanzees (Pan troglodytes): vocalizing at the edge. The Journal of the Acoustical Society of America 121:1758-1767.

Riessen, H. P., AND W. G. Sprules. 1990. Demographic costs of antipredator defenses in Daphnia pulex. Ecology 71:1536-1546.

Rohwer, S., S. D. Fretwell, and R. C. Tuckfield. 1976. Distress screams as a measure of kinship in birds. American Midland Naturalist 96:418-430.

Schuett, G. W., And J. C. Gillingham. 1990. The function of scream calling in nonsocial vertebrates: testing the predator attraction hypothesis. Bulletin of the Chicago Herpetological Society 25:137-142.

Sikes, R. S., and the Animal Care and Use Committee of the American Society of Mammalogists. 2016. 2016 Guidelines of the American Society of Mammalogists for the use of wild mammals in research and education. Journal of Mammalogy 97:663-688.

Venuto, V., V. Ferraiuolo, L. Bottoni, and R. Massa. 2001. Distress call in six species of African Poicephalus parrots. Ethology Ecology \& Evolution 13:49-68.

Vignal, C., AND D. Kelley. 2007. Significance of temporal and spectral acoustic cues for sexual recognition in Xenopus laevis. Proceedings of the Royal Society of London B: Biological Sciences 274:479-488.

Wilden, I., H. Herzel, G. Peters, and G. Tembrock. 1998. Subharmonics, biphonation, and deterministic chaos in mammal vocalization. Bioacoustics 9:171-196.

Submitted 14 May 2018. Accepted 13 June 2019.

Associate Editor was Ricardo Ojeda. 